\title{
Expanding our reach: Cross-institutional collaborations and teacher preparation in
} Hispanic Serving Institutions

\author{
Ana K. Soltero López ${ }^{1}$ and Patricia D. López ${ }^{1 *}$ \\ ${ }^{1}$ California State University, Fresno \\ *Corresponding Author: pdlopez@csufresno.edu \\ Received : 2020-JUNE-01 \\ Accepted : 2020-JUNE-01 \\ DOI: $10.46303 /$ jcve.03.01.8
}

How to cite this paper: Soltero López, A. K., \& López, P. D. (2020). Expanding our reach: Cross-institutional collaborations and teacher preparation in Hispanic Serving Institutions. Journal of Culture and Values in Education, 3(1), 120-135.

\begin{abstract}
This paper addresses the role of cross-institutional collaborations among Hispanic Serving Institutions (HSI). Specifically, we focus on the Enseñamos en el Valle Central Initiative-a five-year, Title V, Developing Hispanic Serving Institutions (DHSI) grant for recruiting and preparing bilingual, Latinx teachers with a strong sense of self and service to their communities. While California four-year state institutions have historically been at the helm of preparing bilingual Kindergarten through 12th grade teachers, this has not been the case for community colleges, which continue to be the first entry point into higher education for many Latinx communities. We discuss how the process of a two-week summer institute among two- and four-year faculty at two community colleges and one University expands conventional notions of teacher preparation, and how these non-normative approaches can lend to stronger pathways into the profession. Moreover, we share how our faculty development approaches disrupt the status quo in teacher preparation and how nontenured Faculty of Color navigate the politics of disruption. Finally, we describe how these race-gendered experiences hold relevance for how we understand teacher preparation and expanding access to underrepresented Teachers of Color into the teaching profession.

Keywords: cross-institutional collaboration, teacher education, Hispanic Serving Institutions, Teachers of Color
\end{abstract}


Soltero López, A. K., \& López, P. D., Expanding our reach: Cross-institutional collaborations and teacher preparation in Hispanic Serving Institutions

\section{Introduction}

This paper adds to the literature by answering the question: What role does teacher preparation and collective partnerships in Hispanic Serving Institutions (HSI) play in extending the reach of institutions in order to more broadly serve Latinx ${ }^{1}$ communities in California?

Nationally, there remain stark gaps in racial/ethnic demographics between students and teachers. In the Kindergarten through 12th grade (K-12) system, Latinx students make up over 24 percent of the student population, yet, Latinx teachers make up only 7.8 percent of the profession (U. S. Department of Education [USDOE], 2016). In fact, nationally, a mere one-tenth of one percent of Latinx students are attending a school system where the portion of Latinx teachers is either equal to or exceeds the percentage of Latinx students (Meckler \& Rabinowitz, 2019). In California, Latinx youth comprise more than half of the total student population in public K-12 schools, making them the largest ethnic group in the state (California Department of Education (CDE), 2016). California is also home to the largest number of Emergent Bilingual ${ }^{2}$ youth-the majority of whom are Latinx-representing 1.3 million (or 22.1\%) of all K-12 student enrollments (CDE, 2016). This mismatch among Latinx teachers and students exceeds that of any other racial or ethnic group in California and no longer can the state avoid K-12 student demographics which are becoming more and more racially diverse (CDE, 2016).

In the context of teacher education, the California State University (CSU) system is the largest producer of K-12 teachers in the state and nationally (CSU, 2019). As a whole, the CSU enrolls 40 percent of the state's Latinx undergraduates (Bustillos \& Sequieros, 2018) and 21 of the 23 CSU campuses are designated as HSIs. Similar to the state's community college system, statewide demographics further reveal that California's college-aged student body is increasingly racially and ethnically diverse-whereby Latinx communities represent a large share. Fresno State, the university discussed in this chapter, is located in the California Central Valley. Fresno is a mid-size city with a population of a little over half a million people (U.S. Census Bureau) and is surrounded by rural communities, much of which is agricultural. Nestled in the southeast part of northern California, the Central Valley is composed of 10 counties, both rural and urban, and includes the Sequoia and Yosemite National Parks. The Central Valley constitutes one of the fastest growing regions in the state (CDF, 2018) and these demographic shifts are forcing four-year institutions and university teacher education programs to reexamine recruitment and retention approaches, particularly with regard to Teachers of Color (TOC).

Related to California's demographic trends are monumental policy changes that arguably lend to expanded institutional conceptions and opportunities for serving Latinx

\footnotetext{
${ }^{1}$ The term Latinx is used in lieu of Latina, Latino, or Latina/o to represent gender-neutral and nonbinary identities.

${ }^{2}$ Emergent Bilingual is an asset-based term for children who are learning a second language, such as English. Typically, these children are labeled as English Language Learners (ELL) or Limited English Proficient (LEP). Unlike Emergent Bilingual, these terms are deficit-based because they focus on the lack of English, whereas, Emergent Bilingual, celebrates their native language and their ability to become bilingual.
} 
communities. The 2016 passage of Proposition 58, which reinstated bilingual education and has led to a growing demand for bilingual/dual language classrooms and bilingual teachers. This shift is also opening new opportunities for teacher preparation programs. Adding to this climate is California's evolving implementation of required Ethnic Studies curricula in high school campuses, which will expose students to the history and numerous contributions and accomplishments of People of Color. Together, these contexts inform the impetus and focus of California State University, Fresno's (Fresno State) Enseñamos en el Valle Central Initiative-a five-year Title V, Developing Hispanic Serving Institutions (DHSI) grant for preparing bilingual, self-reflective, and critically conscious Latinx teachers with a strong sense of self and service to their communities.

Central to the Enseñamos Initiative is the goal of recruiting high school Latinx youth, as well as current community college enrollees, into a pathway to teaching. As a pathway project, Enseñamos en el Valle Central focuses on supporting bilingual, high school Latinx youth to enter and persist though Community College teacher education pathways and into a four-year degree and multiple subject credential and bilingual authorization at California State University, Fresno (CSUF) located in California's Central Valley. This pathway approach translates to prospective teacher candidates having to navigate multiple systems and faculty (i.e., K-12, community college, and four-year institutions). This trajectory includes an array of non-teacher-education faculty, courses, and epistemological standpoints that arguably have a direct bearing on the journeys of future teacher candidates. As a result, a two-week institute was created to support faculty under the auspices of strengthening Latinx candidates' access to the profession.

The Enseñamos summer institute is situated in historical struggles to diversify the teaching profession and affirm the community-based identities of Teacher Candidates of Color. With that said, the summer institute pushes back and redefines teacher education by establishing intentional and purposeful cross-institutional collaborations between two- and four-year professors who play integral roles in the persistence of bilingual and Latinx teacher candidates. It is designed with the intent to be a safe space for critical dialogue where faculty are supported to intellectualize their practices by defining their identities, teaching philosophies, owning their epistemologies, and co-constructing culturally and linguistically sustaining curriculum and pedagogies for Teacher Education-related courses. This includes centering the lived experiences of minoritized youth as transformative, empowering, and sustainable forms of teaching and learning. While research argues the value and merits of reflective practice as foundational elements of effective teachers and teaching (Boud \& Walker, 1998; Calderhead \& Gates, 1993; Gore \& Zeichner, 1991; Hatton \& Smith, 1995), encouraging educators to dismantle and become reflective is not an easy task. These realities make the efforts of the Enseñamos Initiative a noteworthy disruption of the status quo and a shift to address a significant academic and societal void.

Part of critically analyzing racial/ethnic gaps in the teaching profession involves examining the role of disruptive approaches that push back against traditional norms in higher education and the preparation of preservice teachers, and the positive implications that these actions hold for Latinx and underrepresented teacher candidates. Namely, in this chapter we discuss teacher preparation faculty discomforts discussing race, language, 


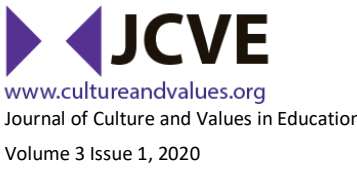

Soltero López, A. K., \& López, P. D., Expanding our reach: Cross-institutional collaborations and teacher preparation in Hispanic Serving Institutions

gender, class, and privilege, and how these factors shape their course design and pedagogy. As part of this discussion, we argue that our efforts expand conventional notions of teacher preparation by developing faculty pedagogy - particularly as it relates to disrupting teachers' belief structures that research argues creates a "filtering effect" through which new ideas and knowledge are processed, interpreted, and implemented in practice (Pajares, 1992). Moreover, we reveal how reaching back and viewing teacher preparation prior to enrollment in a four-year, credential program broadens our understanding of access to the profession generally, and more specifically for Latinx and under-represented Teachers of Color. With that said, the implications of our findings broaden our understanding of how faculty establish and develop their pedagogical stance and how these beliefs dictate actions in the classroom.

As part of our findings, we also highlight how our faculty development approaches seek to disrupt the status quo in teacher preparation and push forward "a serious transformation or alteration of the structure of teaching and learning activities taking place in formal education" (Munro, 2008, p. 476). Moreover, we share how the politics of disruption also brings about challenges and barriers, particularly for untenured faculty. In our case, as two untenured Faculty of Color, traversing the political terrains has required us to devise unique strategies to mitigate pushback as we challenge the existing culture of academia and teacher preparation. These race-gendered experiences among Faculty of Color hold relevance for how we understand teacher preparation generally, and efforts to expand access to underrepresented Teachers of Color into the teaching profession.

\section{Benefits and Experiences of Teachers of Color}

White teachers continue to make up the majority of the $\mathrm{K}-12$ teaching population, representing a large portion of teacher education research (Cochran-Smith et al., 2015). An expression of this dominance much of the literature in teacher education is focused more on how to prepare and assist current teacher demographics to teach these Latinx and minoritized communities (Brown, 2014; Cochran-Smith et al., 2015, Sleeter, 2001). Moreover, this emphasis often operates within the constructs of teacher quality and accountability, which are tightly coupled to top-down policies related to certification, testing, and assessment and less inspired by examinations of racial, linguistic, or sociopolitical aspects of teacher education (Cochran-Smith \& Villegas, 2015).

In those cases where research has examined Latinx and Teachers of Color specifically, analyses reveal that having Latinx and bilingual teachers is a critical school-based factor associated with students' academic trajectories (Villegas \& Irvine, 2010). Research shows that Latinx teachers are in part drawn to the profession because of their personal experiences witnessing the rampant deficit thinking that permeates schooling practices and a sense of social responsibility toward the empowerment of Students of Color (Kohli, 2009). While Teachers of Color generally, and Latinx teachers specifically, remain underrepresented relative to K-12 student populations, research shows that their presence matters. In particular, research reveals three pertinent, empirically-based benefits that Teachers of Color contribute to K-12 schooling: first, they serve as role models to all 
Soltero López, A. K., \& López, P. D., Expanding our reach: Cross-institutional collaborations and teacher preparation in Hispanic Serving Institutions

students; second, Teachers of Color are more likely to work in high minority-serving schools whereby curbing particular teacher shortages that these contexts often face; and finally, many Teachers of Color bring a deep understanding of the racial/ethnic and cultural experiences of Students of Color (Villegas \& Irvine, 2010).

Research reveals that Teachers of Color are more likely to value and build upon students racial/ethnic identities, participate in consistent and implicit affirmation (Darder, 1993; Howard, 2020; Uhlenberg \& Brown, 2002; ) and "racial microaffirmations," that benefit students and also influence positive shifts in school climate (Rolón-Dow \& Davison, 2018). Finally, Teachers of Color are more likely to utilize culturally and linguistically sustaining pedagogies, drawing from cultural frames of reference and daily lived experiences in order to make the learning process meaningful, which in turn allows them to develop positive and caring teacher-student relationships with Students of Color (Dee, 2005; Irizarry \& Donaldson, 2012; Monzo \& Rueda, 2001; Nieto, 2005; Paris \& Alim, 2017). Research also shows that Teachers of Color are more likely to be sought after among Students of Color as role models (Cherng \& Halpin, 2016; Quiocho \& Ríos, 2000). These important contributions can sometimes induce added duties and workload, while at the same time creating hostile racial climates that mirror the experiences of Students of Color in K-12 schools (Amos, 2016; Kohli, 2018; Pizarro \& Kohli, 2018). Related to the realities and experiences of Teachers of Color in K-12 schools is national data revealing that these groups are pushed out of the profession at higher rates than their White counterparts (Ingersoll \& May, 2011). In California, data reflect this trend in that Latinx teachers are pushed out of the profession at rates far greater than other subgroups (Griffin, 2018).

Similar pushout experiences also occur during the preparation process of Latinx candidates. For one, these candidates are forced to negotiate the taxation of Whiteness - or the "ascribed privilege that exempts Whites from discussions on race, creates the possibility for White professors and students to circumvent the deep effects of race on others and themselves" (Chávez-Reyes, 2012, p. 46). Moreover, Latinx candidates must contend with economic exclusion, standardized testing, and racially-biased conceptions of teacher quality that maintain and acquiesce to Whiteness at their expense (Rogers-Ard, 2012). High tuition costs and exuberant fees related to a battery of exams required by the state of Californiai.e., California Basic Education Skills Test (CBEST), California Subject Examination Test (CSET), and the Reading Instruction Curriculum Assessment (RICA) - further perpetuate the racial imbalance in the teaching force. Taken together, these patterns call attention to the need for greater racial/ethnic- and culturally-responsive, systems as integral parts of recruitment and preparation processes at multiple sites.

\section{Context of Study}

The Enseñamos en el Valle Central Initiative is a five-year Title V, Developing Hispanic Serving Institutions (DHSI) grant focused on recruiting and preparing bilingual, Latinx teachers with a strong sense of self and service to their communities. Title $\mathrm{V}$ of the Higher Education Act (1965) defines HSIs as two- and four-year colleges and universities that have an enrollment of at least 25 percent of students that identify as Hispanic and at least 50 
percent from a low-SES background (Baez, et al., 2008). In collaboration with Fresno State's two largest community college feeder schools, our overarching framework is focused on expanding pathways into the teaching profession by strengthening recruitment and student support services, improving curricular options and pedagogical practices, and institutionalizing partnerships that expand the capacity of two- and four-year institutions to better serve minoritized, and in our case, bilingual Latinx teacher candidates.

A central component of the Enseñamos en el Valle Central Initiative, the summer institute and subsequent professional learning community (PLC) draws from the tenets of culturally sustaining pedagogies (CSP; see Paris \& Alim, 2017) and Chicanx/Latinx Studies frameworks to support community college and university faculty whose courses are part of the teacher education pathway. Culturally sustaining pedagogy builds upon the early work of Gloria Ladson-Billings (1995) who asserts that "culturally relevant teaching must meet three criteria: an ability to develop students academically, a willingness to nurture and support cultural competence, and the development of a sociopolitical or critical consciousness" ( $p$. 483). Paris and Alim (2017) further expanded on this work, arguing for a needed shift in pedagogical theory and practice that sustains the three tenets of linguistic, literate, and cultural pluralism. Thus, these principles seek to denormalize the Whiteness, biased, assimilationist, anti-intellectual, and monolingual policies, practices, and pedagogy that continue to operate in schooling today to the detriment of Students of Color. As a theory and practice, CSP is about empowering Students of Color and positively transforming their educational experiences.

The two-week summer institute brought together faculty from two- and four-year institutions and across-disciplines to co-construct curriculum and pedagogy that was purposefully grounded in the culture, language, histories, and racialized experiences of Latinx and minoritized students. The institute was described as, "a safe space for critical dialogue where faculty are supported to intellectualize their practices by defining their teaching philosophies, owning their epistemologies, and co-constructing culturally and linguistically sustaining curriculum and pedagogies for Teacher Education-related courses." Similar to the argument that transformational change does not occur by way of a single course or intervention, we understand that prolonged engagement among faculty is key. Following the summer institute, we established a professional learning community throughout the academic school year among participating faculty that includes professional development focused on integrating culturally sustaining and Chicanx/Latinx/Ethnic Studies curriculum and pedagogy, as well as bilingual concentrations into lower-division community college and upper-division Liberal Studies coursework.

Applying a CSP framing we draw from quantitative and qualitative data to reveal how cross-institutional collaborations disrupt conventional notions of teacher preparation for Latinx communities. Moreover, we were interested in understanding how complexities of educator identities find expression in their pedagogical practices, and how these situated experiences operate within broader sociocultural and sociopolitical contexts of teaching and learning (Lortie, 2002). Guiding our inquiry are the following overarching research questions: 
Volume 3 Issue 1, $2020 \quad$ Soltero López, A. K., \& López, P. D., Expanding our reach: Cross-institutional collaborations and teacher preparation in Hispanic Serving Institutions

1. How do cross-institutional faculty development approaches expand conventional notions of teacher preparation and what are the implications for minoritized, Candidates of Color?

2. What are the politics faced by untenured, Women of Color faculty when implementing non-normative approaches in teacher preparation?

Recruitment of faculty participants was facilitated by the Enseñamos en el Valle Central Project Director, as well as campus Deans and assigned faculty coordinators from the two- and four-year participating institutions. All faculty applied to be part of the institute and were provided a clear overview of the scope and structure. They were also provided IRB documents and gave consent to allow their participation to inform our broader research agenda and grant deliverables.

Faculty participants were sent a formal invitation that included an overview and structure of the two-week institute and the stipend amount attached to their participation. Faculty who were interested in applying were asked to submit a short application that included a statement of their teaching philosophy, a current syllabus, and responses to a pre-institute survey where they self-rated their knowledge and use of three overarching domains: Community Cultural Wealth of minoritized communities; Culturally Sustaining Pedagogies -including issues of translanguaging ${ }^{3}$ and raciolinguistics ${ }^{4}$; and, Online, Hybrid, and Open Educational Resources ${ }^{5}$ (OER).

The two-week summer institute involved 13 faculty representing the following disciplines: Political Science, English, Mathematics, Communications, Child Development, Chicanx Studies, and Teacher Education. The first week consisted of three asynchronous online modules. The first focused on reflections of working with bilingual students in which they read Tara Yosso's (2005) community cultural wealth article. The second module focused on CSP and translanguaging with the goal of understanding the relationship between language and education from a sociolinguistic perspective. This module included a chapter on translanguaging by Ofelia Garcia and Tatyana Kleyn (2016) and a chapter on CSP by Django Paris and H. Samy Alim (2017). After completing these readings, participants were asked to annotate the areas of strengths and areas of growth on their syllabi as they pertain to CSP and translanguaging. Module three focused on cultivating authentic classroom experiences. For this module, faculty learned about Open Educational Resources (OER) and reflected on how they can adopt the content of the week into their pedagogy.

The second face-to-face week was designed to go into greater depth using lectures, small and large group discussions, reflections, and time for peer-review feedback and revisions to course syllabi. Faculty consent was confirmed before data collection ensued. One of the first activities of this week was discussing identities, how they are developed,

\footnotetext{
${ }^{3}$ Translanguaging refers to the dynamic language practices of bilingual/multilingual people. This term differs from code-switching which views speakers accessing two different language repertoires, whereas translanguaging believes that multilingual people possess only one language repertoire (see Garcia, Ibarra Johnson, \& Seltzer, 2016).

${ }^{4}$ Raciolinguistics refers to the examination of the intersection between race and language, resulting in the racialization of language.

${ }^{5}$ Open Educational Resources refers to free, no cost materials for courses.
} 
Soltero López, A. K., \& López, P. D., Expanding our reach: Cross-institutional collaborations and teacher preparation in Hispanic Serving Institutions

who influences them, how they affect the way we experience the world, and how they shape our interactions with others. Following this discussion, faculty created an identity map where they annotated identity markers such as race/ethnicity, gender, and socioeconomic status, just to name a few. In groups, they then discussed which of their identities are privileged, marginalized, public v. private, and intersecting and how they believe they are reflected in their teaching, curriculum, and interactions with students. This activity transitioned to a discussion of the Yosso article and the importance of recognizing, validating, and incorporating the six forms of capital discussed in the article. Discussion of Yosso's (2005) linguistic capital was bridged with a discussion of translanguaging and raciolinguistics and what this looks like in the classroom setting. The culminating activity of the summer institute had faculty examine their syllabus and identify areas in which they can expand to include the materials and topics that were discussed at the institute to make them more responsive to future bilingual teachers.

\section{Findings}

Our collaborative approach acknowledges that developing and sustaining cultural and linguistic awareness among teacher candidates cannot rest on the shoulders of a single course (Haddix, 2008). Rather, the entire breadth of coursework-in our case from community college to four-year, and credential-must be grounded in culturally sustaining repertoires, including embedded community-based experiences as spaces of application (McDonald et al., 2011). With that said, resources to support community college and Fresno State faculty who seek to situate their content with a strong emphasis on culturally sustaining curriculum and pedagogy, including translanguaging practices, that are responsive to the needs of Latinx and bilingual students.

Finally, as non-tenured Faculty of Color, how we navigate the politics of working with faculty of all ranks while interrogating problematic ways of knowing and reductive approaches in the preparation of bilingual Latinx teacher candidates is relevant. Engaging in disruptive practices for Faculty of Color is always nested in a long history of presumed incompetency and efforts to delegitimize race-gendered voices in academia (Gutierrez y Muhs et al., 2012). The act of leading disruptive practices for social change in teacher preparation requires explicit and intentional strategies that exceed mere knowledge of the non-normative practices you are seeking to change. These strategies, we argue, are direct expressions of Women of Color epistemologies that are relevant to how we understand and continue to interrogate teacher preparation.

\section{Disrupting Conventional Notions of Teacher Preparation and Access for Teachers of Color}

Analysis of course syllabi, surveys, and discussions revealed the varying degrees of impact that the summer institute had on faculty subjectivities, beliefs, and pedagogy. Findings reveal faculty discomfort in discussing race, gender, class, privilege and power and how these factors shape their course design and pedagogy. Moreover, community cultural wealth, CSP, translanguaging, state standards and requirements were new to many of the participating faculty. This further underscores the necessity of expanding conventional 
Volume 3 Issue 1, $2020 \quad$ Soltero López, A. K., \& López, P. D., Expanding our reach: Cross-institutional collaborations and teacher preparation in Hispanic Serving Institutions

notions of teacher preparation pipelines and how the Enseñamos Initiative is disrupting this practice.

Analysis of initial faculty course syllabi submitted prior to the summer institute revealed that faculty had little to no evidence of course readings or assignments that reflected CSP. Responses to the pre-questionnaire and daily reflections indicated conflicting messages about CSP. For example, when asked to briefly explain culturally sustaining pedagogy in their own words, faculty described it as follows:

Teaching in a way that demonstrates to students that their cultural heritages, experiences, communities, and families are an asset to learning. Teaching that uplifts communities of color rather than showing that students need to shed their backgrounds to 'make it.' Pedagogical tools that incorporate students' diverse racial, linguistic, and community identities.

and,

CSP is the continuing process of 1 ) being aware of the diverse backgrounds of your students, 2) including these perspectives in daily lessons, and 3) including your own cultural identity in your teaching.

When asked, How engaged are you in employing a culturally sustaining lens when designing learning experiences for your students? (using Likert scale responses 1 to 6 ; 1 being, "I consider myself 'color-blind' and 'culture-blind"” and, 6 being, "I incorporate my students' cultural and linguistic backgrounds into my classroom practice"), half of respondents selfidentified with a color-blind and culture-blind pedagogy and half with a CSP pedagogy.

Similarly, most faculty were learning about translanguaging for the first time. When asked to explain translanguaging in their own words, some responses included, "I think it's the idea where we switch from casual talk to formal talk. I'm honestly not sure though" and, "This is the shifting between languages in the process of discerning ideas in learning spaces." When asked, How engaged are you in employing a translanguaging lens when designing learning experiences for your students? (using Likert scale responses 1 to 6; 1 being, "Never heard of it" and, 6 being, "I design each lesson/activity using translanguaging principles"), the majority of participants identified not knowing about this concept.

Moreover, the pre-institute survey also revealed that faculty had limited familiarity and understanding of the Associates degree to transfer in Liberal Studies/Teacher Education program at the community college level, the state's subject matter content specifications and state standards in their respective field, as well as the required state credential assessments for teachers. These findings are telling and emphasize the need to develop faculty pedagogy. In the context of the Enseñamos Initiative, this is crucial as all participating faculty teach the cohorts of Enseñamos students in their journey from the community college through the completion of the multiple subject credential program. The goal of the summer institute reflects Blin and Munro's (2008) definition of disruption as “a serious transformation or alteration of the structure of teaching and learning activities taking place in formal education" (p. 476). Challenging and disrupting educator beliefs is central to the principles of this initiative. Investigating the social location and sociopolitical context of faculty and how it influences their pedagogy was achieved through an identity mapping activity. The activity was described as an opportunity to unpack their multiple identities and 
reflect on the influence of those identities to their pedagogy. Relatedly, this module encouraged faculty to begin analyzing their syllabus in relation to their complex identities and those of the bilingual Latinx students they serve generally and will serve through this initiative.

Analysis of faculty identity maps and discussions during the face-to-face week revealed hesitation to openly disclose and discuss identities such as race/ethnicity, culture, socioeconomic status, among other characteristics, and how these subjectivities are consciously or unconsciously represented in course syllabi, assignments, pedagogy, and interactions with students. Though they were instructed to identify the top three identities they believe are the most salient to their teaching, faculty rarely selected identities such as race, class, or gender and when probed by facilitators to consider the influence of those characteristics, they shied away from the discussion. Faculty demonstrated difficulty articulating how each of their self-prescribed identities influenced their curriculum design and teaching. This discomfort was further amplified when participants were asked to reflect on their privilege and power over students. This uncomfortable, but necessary conversation looped back to our discussion on the numerous inequities that affect Students of Color, and in the case of this initiative, prevent aspiring bilingual Latinx youth from achieving their dream of becoming teachers.

As we collaborated with faculty during the summer institute, we gained insights on how unaware faculty are of the various hurdles and stages students are required to navigate in order to access the profession. Participants reflected and shared daily on how detached their coursework is from the expectations that teacher pathway students would ultimately need to fulfill. These realities underscore the critical role of faculty development as it relates to expanding access to Latinx and under-represented candidates into the initial stages of the teaching profession.

\section{Women of Color Epistemologies and Non-Normative Approaches in Teacher Preparation}

Enseñamos en el Valle Central and the initiative's summer institute do not operate in isolation. Understanding the approaches utilized to disrupt traditional norms among faculty working with teacher candidates must consider the social location of the actors who employ them. Moreover, our practices and what we consider disruptive are also situated in specific space and time, which in our case consisted of major policy shifts and growing discourses that claimed to be invested in diversifying the profession. In the initial planning of the summer institute, we were made aware of the political contentions that coincide with culturally sustaining and anti-racist perspectives. We observed how these dispositions were colliding with presumed incompetencies projected onto Latinx and minoritized students attending our two partnering community college campuses as they were transitioning to career-specific Associate Degree Transfer (ADT) articulation agreements.

In theory, California community college's ADT program provides structural circumstances that can potentially strengthen a student's hand as they traverse through the impacted transfer gauntlet, whereby dismantling the historic and endemic "cooling out" function in two-year colleges (Clark, 1960; Crisp \& Nuñez, 2014). Until the state's shift to career-specific associate degrees for transfer agreements, the idea of preparing and 
Volume 3 Issue 1, $2020 \quad$ Soltero López, A. K., \& López, P. D., Expanding our reach: Cross-institutional collaborations and teacher preparation in Hispanic Serving Institutions

supporting aspiring teacher candidates in California's community college system were not central to the vision of these campuses. Through the Enseñamos Initiative, we were able to observe that as the evolution of California ADTs moved from theory to practice, it is not enough to have clear articulations. While students can be advised and kept on track with regard to course sequencing and completion, what occurs in those courses from a curriculum and pedagogy standpoint are also critical. With that said, our efforts to extend knowledge about the profession and develop extracurricular opportunities to help future Latinx candidates become acquainted with the requirements to matriculate to a four-year university teacher preparation program, do not equate to them being successful, let alone thriving.

Going into this climate and acknowledging the historical and contemporary norms operating at our partnering community colleges, our first strategy consisted of establishing a core group of ally faculty-both tenured and non-tenured-who could help to reinforce central tenets of culturally sustaining epistemologies while at the same time relieving some of the pressure that would otherwise fall on us as facilitators. The act of facilitating difficult discussions that interrogate problematic ways of knowing and reductive approaches when working with minoritized Students of Color can come with a cost. The core group was integral to ensuring that we were not cast as the sole voice of race-conscious and disruptive discourses or reduced to mere personal opinions. Also, as a strategy of intentionality, we were able to maintain a level of power while shielding ourselves from unproductive ideological debates that are often weaponized by faculty who dissent.

Initially, we drew from a strategy of intentionality and establishing a core group of faculty as a method for overcoming barriers and challenges. During the course of the summer institute, we observed that our core group's reflective practices and articulations of challenging normative conceptions of curriculum and pedagogy inspired critical crossdisciplinary dialogues that resonated with community college faculty. The openness among our core faculty whose course content is grounded in the histories, experiences, and raciallinguistic epistemologies of Latinx communities though admittingly can be stronger with regard to pedagogy and how students (i.e., future teacher candidates) actually teach. This authentic admission contributed to all faculty sharing similar shortcomings and letting down their guard, while at the same time shed light on the important contributions that faculty from area studies bring to the process of teacher preparation.

Our collaborations with community colleges reveal that these campuses rely heavily on student services to "fix" breaks in persistence often avoiding professional development interventions with community college faculty. Moreover, intervention on curriculum and instruction are bound to the fact that faculty have a choice on whether or not they want to participate. Adding to this is the intense teaching load-which for community college faculty in California constitutes the entirety of their collectively bargained contracts, as well as their promotion and tenure evaluations and reappointments. These circumstances create initial barriers by leaving little to no room for faculty to reflect on their classroom practices relative to serving minoritized students, let alone re-envision their lower-division courses as part of a teacher preparation pathway-all of which plays a role in filtering out talented Latinx 
Volume 3 Issue 1, $2020 \quad$ Soltero López, A. K., \& López, P. D., Expanding our reach: Cross-institutional collaborations and teacher preparation in Hispanic Serving Institutions

teacher candidates far before they even reach four-year and post-baccalaureate teacher prep programs.

One of our critical strategies for overcoming institutional barriers that can render disruptive practices optional and maintain traditional norms in higher education was to invite and establish relationships with senior ranked community college faculty that hold strong union affiliations. Navigating the nuances of community college's collective bargaining agreements as they relate to academic freedom, what justifies professional development, and the unwritten culture of faculty development are key. From a structural perspective, we found that the community college system provides sparse availability and options to support faculty in general, and even less when it comes to responding to the shift to career-specific ADT pathways such as teacher preparation. This void arguably connects to a broader goal of increasing access into the profession for Latinx and underrepresented communities in California.

\section{Conclusion}

Enseñamos en el Valle Central represents a Latinx teacher pathway project that demonstrates how cross-institutional collaboration among two- and four-year institutions that center on anti-racism, language, gender, class, and privilege hold positive implications for higher education and the preparation of preservice teacher candidates. However, these investments are more commonly available to faculty from four-year universities and less so for two-year community colleges, which remain the first entry point into higher education among Students of Color. Adding to these disparities are the demands that faculty at twoyear HSI institutions must negotiate which often create time constraints and obstacles for participating in professional development. In the case of California specifically, where evolving policy shifts are establishing explicit transfer pathways into teacher preparation, true investments that will allow two-year faculty to revitalize their courses to support students that aspire to enter the profession are needed and arguably integral to broader discussions related to the teacher pipeline. These same policy shifts also provide opportunities for teacher education to expand its view of teacher preparation pathways and access to the profession. These broader conceptualizations of teacher pathways that affirm spaces prior to four-year university enrollment are particularly germane for access to the profession generally, and more specifically for under-represented Teachers of Color-all of which remain priority areas for the field.

Disrupting traditional norms in higher education and teacher preparation does not occur in a vacuum. Rather, navigating the politics of disruption requires a methodology that in our case involves explicit strategies that are situated and take into account external factors. With regard to non-tenured Faculty of Color who are leading faculty development efforts that are grounded in nontraditional practices, these strategies are especially important for providing political coverage during instances of discomfort and pushback from faculty. These same considerations are also important for broader efforts that seek to disrupt historical barriers that continue to marginalize access to the profession. 
Soltero López, A. K., \& López, P. D., Expanding our reach: Cross-institutional collaborations and teacher preparation in Hispanic Serving Institutions

\section{References}

Acevedo-Gil, N., Santos, R. E., \& Solórzano, D. G. (2014). Examining a rupture in the Latina/o college pipeline: Developmental education in California community colleges. PERSPECTIVAS Issues in Higher Education Policy and Practice, 3, 1-19.

Amos, Y. T. (2016). Voices of teacher candidates of color on white race evasion: 'I worried about my safety!' International Journal of Qualitative Studies in Education, 29(8), 1002-1015. https://doi.org/10.1080/09518398.2016.1174900

Baez, B., Gasman, M., \& Turner, C. S. V. (2008). On minority-serving institutions. In M. Gasman, B. Baez, \& C. S. V. Turner (Eds.), Understanding minority serving institutions, (pp. 3-17). State University of New York Press.

Blin, F., \& Munro, M. (2008). Why hasn't technology disrupted academics' teaching practices? Understanding resistance to change through the lens of activity theory. Computers \& Education, 50(2), 475-490. https://doi.org/10.1016/j.compedu.2007.09.017

Boud, D. \& Walker, D. (1998). Promoting reflection in professional courses: The challenge of context. Studies in Higher Education, 23(2), 191-206. https://doi.org/10.1080/03075079812331380384

Brown, K. D. (2014). Teaching in color: A critical race theory in education analysis of the literature on preservice teachers of color and teacher education in the U.S. Race, Ethnicity and Education, 17(3), 326-345. https://doi.org/10.1080/13613324.2013.832921

Bustillos, T. B. \& Sequieros, M. (2018). Left out: How exclusion in California's colleges and universities hurts our values, our students, and our economy. The Campaign for College Opportunity. https://collegecampaign.org/portfolio/left-out-report/

Calderhead, J. \& Gates, P. (Eds.) (1993). Conceptualizing Reflection in Teacher Development. Falmer Press.

California State University (CSU). (2020). The California State University Factbook 2020. The California State University.

Chávez-Reyes, C. (2012). Engaging in critical social dialogue with socially diverse undergraduate teacher candidates at a California State University. Teacher Education Quarterly, 39(2), 43-62. https://www.jstor.org/stable/23479671

Cherng, H-Y. S. \& Halpin, P. F. (2016). The importance of minority teachers: Student perceptions of minority versus White teachers. Educational Researcher, 45(7), 407420. https://doi.org/10.3102/0013189X16671718

Clark, B. R. (1960). The "cooling-out" function in higher education. The American Journal of Sociology, 65(6), 569-576. https://doi.org/10.1086/222787

Cochran-Smith, M. \& Villegas, A. M. (2015). Framing teacher preparation research: An overview of the field, Part 1. Journal of Teacher Education, 66(1), 7-20. https://doi.org/10.1177/0022487114549072

Cochran-Smith, M., Villegas, A. M., Abrams, L., Chavez-Moreno, L., Mills, T., \& Stern, R. (2015). Critiquing teacher preparation research: An overview of the field, Part II. 
Volume 3 Issue 1, $2020 \quad$ Soltero López, A. K., \& López, P. D., Expanding our reach: Cross-institutional collaborations and teacher preparation in Hispanic Serving Institutions

Journal of Teacher Education, 66(2), 109-121.

https://doi.org/10.1177/0022487114558268

Crisp, G. \& Nuñez, A. M. (2014). Understanding the racial transfer gap: Modeling underrepresented minority and nonminority students' pathways from two to fouryear institutions. The Review of Higher Education, 37(3), 291-320. https://doi.org/10.1353/rhe.2014.0017

Darder, A. (1993). How does the culture of the teacher shape the classroom experience of Latino students? The unexamined question in critical pedagogy. In S. W. Rothstein (Ed.), Handbook of Schooling in Urban America (pp. 195-221). Greenwood.

Dee, T. S. (2005). A teacher like me: Does race, ethnicity, or gender matter? American Economic Review, 95(2), 158-165. https://www.jstor.org/stable/4132809

Ek, L. D., Quijada Cerecer, P. D., Alanis, I., \& Rodriguez, M. A. (2010). “I don't belong here": Chicanas/Latinas at a Hispanic Serving Institution creating community through Muxerista mentoring. Equity and Excellence in Education, 43(4), 539-553. https://doi.org/10.1080/10665684.2010.510069

Garcia, O., Ibarra Johnson, S., \& Seltzer, K. (2016). The translanguaging classroom: Leveraging student bilingualism for learning. Caslon Publishing.

Gore, J. M., \& Zeichner, K. M. (1991). Action research and reflective teaching in preservice teacher education: A case study from the United States. Teaching and Teacher Education, 7(2), 119-136. https://doi.org/10.1016/0742-051X(91)90022-H

Griffin, A. (2018). Our stories, our struggles, our strengths: Perspectives and reflections from Latino teachers. The Education Trust.

Gutiérrez y Muhs, G., Niemann, Y. F., González, C. G., \& Harris, A. P. (2012). Presumed incompetent: The intersections of race and class for women in academia. Utah State University Press.

Haddix, M. (2008). Beyond sociolinguistics: Towards a critical approach to cultural and linguistic diversity in teacher education. Language and Education, 22(5), 254-270. https://doi.org/10.1080/09500780802152648

Howard, T. (2020). Why race and culture matter in schools: Closing the achievement gap in America's classrooms (2nd ed.). Teachers College Press.

Ingersoll, R. M., \& May, H. (2011). Recruitment, retention and the minority teacher shortage. Consortium for Policy Research in Education. https://repository.upenn.edu/gse_pubs/226/

Irizarry, J. \& Donaldson, M. L. (2012). Teach for América: The Latinization of U.S. schools and the critical shortage of Latina/o teachers. American Educational Research Journal, 49(1), 155-194. https://doi.org/10.3102/0002831211434764

Johnson, H., Jackson, J. \& Cuellar Mejia, M. (2017). Making college affordable. Public Policy Institute of California.

Kohli, R. (2009). Critical race reflections: Valuing the experiences of teachers of color in teacher education. Race Ethnicity and Education, 12(2), 235-251.

https://doi.org/10.1080/13613320902995491 
Volume 3 Issue 1, $2020 \quad$ Soltero López, A. K., \& López, P. D., Expanding our reach: Cross-institutional collaborations and teacher preparation in Hispanic Serving Institutions

Kohli, R. (2018). Behind school doors: The impact of hostile racial climates on urban teachers of color. Urban Education, 53(3), 307-333. https://doi.org/10.1177/0042085916636653

Ladson-Billings, G. (1995). Toward a theory of culturally relevant pedagogy. American Educational Research Journal, 32(3), 465-491. https://doi.org/10.3102/00028312032003465

Lortie, D. C. (2002). Schoolteacher: A sociological study. The University of Chicago Press.

McDonald, M., Tyson, K., Brayko, K., Bowman, M., Delport, J., \& Shimomura, F. (2011). Innovation and impact in teacher education: Community-based organizations as field placements for preservice teachers. Teachers College Record, 113(8), 1668-1700. https://eric.ed.gov/?id=EJ988297

Meckler, L. \& Rabinowitz, K. (2019, December 27). America's schools are more diverse than ever. But the teachers are still mostly white. Washington Post. https://www.washingtonpost.com/graphics/2019/local/education/teacher-diversity/

Monzo, L. \& Rueda, (2001). Professional roles, caring, and scaffolds: Latino teachers' and paraeducators' interactions with Latino students. American Journal of Education, 109(4), 438-471. https://doi.org/10.1086/444335

Nieto, S. (2005). Schools for a new majority: The role of teacher education in hard times. The New Educator, 1(1), 27-43. https://doi.org/10.1080/15476880490447797

Pajares, M. F. (1992). Teachers' beliefs and educational research: Cleaning up a messy construct. Review of Educational Research, 62(3), 307-332. https://doi.org/10.3102/00346543062003307

Paris, D., \& Alim, H. S. (2017). Culturally sustaining pedagogies: Teaching and learning for justice in a changing world. Teachers College Press.

Pizarro, M. \& Kohli, R. (2018). “I stopped sleeping': Teachers of color and the impact of racial battle fatigue. Urban Education, $0(00), 1-25$. https://doi.org/10.1177/0042085918805788

Quiocho, A. \& Ríos, F. (2000). The power of their presence: Minority group teachers and schooling. Review of Educational Research, 70(4), 485-528. https://doi.org/10.3102/00346543070004485

Rogers-Ard, R., Knaus, C. B., Epstein, K. K., \& Mayfield, K. (2012). Racial diversity sounds nice; Systems transformation? Not so much: Developing urban teachers of color. Urban Education, 48(3), 451-479. https://doi.org/10.1177/0042085912454441

Rolón-Dow, R. \& Davison, A. (2018). Racial microaffirmations: Learning from student stories of moments that matter. Center for the Study of Diversity Research Briefs, 1(4), 1-9.

Sleeter, C. E. (2001). Preparing teachers for culturally diverse schools: Research and the overwhelming presence of Whiteness. Journal of Teacher Education, 52(2), 94-106. https://doi.org/10.1177/0022487101052002002

Uhlenberg, J. \& Brown, K. M. (2002). Racial gap in teachers' perceptions of the achievement gap. Education and Urban Society, 34(4), 493-530. https://doi.org/10.1177/00124502034004006 
U.S. Census Bureau (2018). Hispanic Population to Reach 111 Million by 2060.

https://www.census.gov/library/visualizations/2018/comm/hispanic-projectedpop.html

U.S. Department of Education. (2016). The State of Racial Diversity in the EducatorWorkforce. https://www2.ed.gov/rschstat/eval/highered/racialdiversity/state-racial-diversity-workforce.pdf

Villegas, A. M., \& Irvine, J. J. (2010). Diversifying the teaching force: An examination of major arguments. Urban Review, 42, 175-192. https://doi.org/10.1007/s11256-010-0150-1

Yosso, T. (2005). Whose culture has capital? A critical race theory discussion of community cultural wealth. Race Ethnicity and Education, 8(1), 69-91.

https://doi.org/10.1080/1361332052000341006 